\title{
Seroprevalence of Toxoplasma gondii infection and associated risk factors among pregnant women attending antenatal clinic at the Bamenda Regional Hospital, Cameroon
}

\author{
${ }^{* 1}$ Nguemaïm, N. F., ${ }^{2}$ Takang, W. A., ${ }^{2}$ Dobgima, W. P., ${ }^{2}$ Guebidiang, B. M., ${ }^{3}$ Foumane, P., \\ and ${ }^{4}$ Kamga, F. H. L. \\ ${ }^{1}$ Department of Biomedical Sciences, Faculty of Health Sciences, University of Bamenda, Cameroon \\ ${ }^{2}$ Department of Clinical Sciences, Faculty of Health Sciences, University of Bamenda, Cameroon \\ ${ }^{3}$ Department of Obstetrics and Gynecology, Faculty of Medicine and Biomedical Sciences, University of Yaoundé I, \\ Cameroon \\ ${ }^{4}$ Department of Medical Laboratory Science, Faculty of Health Sciences, University of Bamenda, Cameroon \\ *Correspondence to: ngflorema@yahoo.fr
}

\begin{abstract}
:
Background: Toxoplasma gondii is a ubiquitous, coccidian parasite that causes toxoplasmosis. This infection, if acquired during pregnancy may result in severe damage. It affects a third of the world's population. In many developing countries, its prevalence is unknown, and data concerning its seroprevalence among pregnant women is scarce in our study area. The objective of this study is to determine the seroprevalence of $T$. gondii infection and the associated risk factors among pregnant women attending the antenatal clinic (ANC) at the Bamenda Regional Hospital in Cameroon. The results obtained will be useful in giving an estimate of the prevalence among pregnant women thus informing policy on preventive measures.

Methodology: This is a descriptive cross-sectional study of pregnant women recruited between January and April 2018 using systematic random sampling technique. Socio-demographic data of participants and predisposing factors to toxoplasmosis were collected using a pretested structured questionnaire administered to them. Five milliliters of blood were collected and the serum screened for IgG and IgM antibodies against $T$. gondii using the cassette and buffer immunochromatographic method. The positive IgG cases were tested further by ELISA technique. Data were analyzed using SPSS version 20. Associations between variables were tested by Chi square and $p$ value $<0.05$ was considered statistically significant.

Results: Of 127 women tested, 44 were seropositive for IgG T. gondii infection (34.6\%) by cassette and buffer method and only 1 with both IgG and IgM antibodies $(0.8 \%)$ were found among them with Elisa test. Pet ownership and handling of their litters were risk factors significantly associated with toxoplasmosis $(p=0.013$ and 0.006 respectively). Although the frequencies of consumption of raw dried meat and farming among the subjects were high, their associations with toxoplasmosis were not statistically significant.

Conclusion: The overall seroprevalence of $T$. gondii antibodies among the pregnant women is still high compared with previous finding in the same area (34.6\% for IgG and $0.8 \%$ for IgG and IgM). Pet ownership and handling of their litters were risk factors significantly associated with toxoplasmosis in this study. Screening of pregnant women during ANC and treatment of positive cases, are necessary to prevent congenital infections in the newborn. Health education on how to minimize exposure to the risk factors should be given.
\end{abstract}

Keywords: Risk factors, toxoplasmosis, congenital transmission, serological diagnosis.

Received July 22, 2019; Revised December 2, 2019; Accepted December 17, 2019

Copyright 2020 AJCEM Open Access. This article is licensed and distributed under the terms of the Creative Commons Attrition 4.0 International License (http://creativecommmons.org/licenses/by/4.0), which permits unrestricted use, distribution and reproduction in any medium, provided credit is given to the original author(s) and the source.

\section{Séroprévalence de l'infection à Toxoplasma gondii et des facteurs de risque associés chez les femmes enceintes en visites prénatales à I'Hôpital Régional de Bamenda au Cameroun}

\author{
${ }^{* 1}$ Nguemaïm, N. F., ${ }^{2}$ Takang, W. A., ${ }^{2}$ Dobgima, W. P., ${ }^{2}$ Guebidiang, B. M., ${ }^{3}$ Foumane, P., \\ et ${ }^{4}$ Kamga, F. H. L. \\ ${ }^{1}$ Département des sciences biomédicales, Faculté des sciences de la santé, Université de Bamenda, Cameroun \\ ${ }^{2}$ Département des sciences cliniques, Faculté des sciences de la santé, Université de Bamenda, Cameroun
}


${ }^{3}$ Département d'obstétrique et de gynécologie, Faculté de médecine et des sciences biomédicales, Université de Yaoundé I, Cameroun

${ }^{4}$ Département des sciences de laboratoire médical, Faculté des sciences de la santé, Université de Bamenda, Cameroun

*Correspondance à: ngflorema@yahoo.fr

\section{Résumé:}

Contexte: Toxoplasma gondii est un parasite coccidien omniprésent qui cause la toxoplasmose. Cette infection, si elle est contractée pendant la grossesse, peut entraîner de graves dommages. Elle affecte un tiers de la population mondiale. Dans de nombreux pays en développement, sa prévalence est inconnue, et les données concernant sa séroprévalence chez les femmes enceintes sont rares dans notre zone d'étude. L'objectif de cette étude est de déterminer la séroprévalence de l'infection à $T$. gondii et les facteurs de risque associés chez les femmes enceintes fréquentant la clinique prénatale de l'hôpital régional de Bamenda au Cameroun. Ceci dans l'optique de donner des estimations sur sa prévalence chez ces femmes enceintes et de générer des stratégies à prendre pour des mesures préventives.

Méthodologie: Il s'agissait d'une étude descriptive transversale effectuée de janvier à avril 2018 à l'aide d'une technique d'échantillonnage systématique. Les données sociodémographiques et certains comportements qui prédisposaient les participants à l'infection ont été recueillis à l'aide d'un questionnaire préétabli. Cinq millilitres d'échantillon sanguin ont été prélevés et le sérum a été dépisté pour détecter les anticorps IgG et IgM contre T. gondi en utilisant la méthode cassette et tampon. Les cas positifs d'IgG ont été soumis à la technique ELISA. Les données ont été analysées à l'aide du logiciel SPSS version 20. Les résultats étaient jugés statistiquement significatifs lorsque la valeur p était inférieure à 0,05

Résultats: Des 127 femmes testées, 44 avaient des anticorps IgG pour l'infection à T. gondii à 34,6\% et seulement 1 avait des anticorps IgG et IgM à 0,8 . Les facteurs de risque associés à l'infection étaient la possession et la manipulation des fèces des animaux de compagnie ( $p=0,013$ et 0,006 respectivement). Les proportions concernant la consommation de viande crue séchée et l'agriculture été élevées, mais les associations n'étaient pas statistiquement significatives. Conclusion: La séroprévalence globale des anticorps $T$. gondii chez les femmes enceintes reste élevées dans la région (soit 34,6\% pour I'IgG et $0,8 \%$ pour IgG et IgM). La possession et la manipulation des animaux de compagnie étaient les facteurs de risque importants associés à l'infection. Le dépistage précoce et systématique de l'infection devrait être envisagé pendant la consultation prénatale, et le traitement pour tout cas positif. Une éducation sanitaire sur les façons de réduire au minimum l'exposition aux facteurs de risque devrait être fournie.

Mots clés: Facteurs de risques, toxoplasmose, transmission congénitale, diagnostic sérologique.

\section{Introduction:}

Toxoplasma gondii, the causative agent of toxoplasmosis, infects warm-blooded animals including humans. Seroprevalence studies show that the organism is found in almost every country with different climates and social conditions (1). Globally, about one third of the world's human population is estimated to carry T. gondii parasite (2). Bradyzoites, tachyzoites and the sporozoites in oocysts are the three infectious stages of the coccidium, parasite to all hosts member of the cat family as its definitive host and has a wild range of intermediate hosts including humans (3). Humans usually acquire $T$. gondii infection through consumption of raw or undercooked meat, of improperly washed vegetables and fruits as well as drinking of water which contains oocysts. Moreover, transplacentally tachyzoites infect the fetus in pregnant women $(4,5)$.

Toxoplasmosis is normally asymptomatic in healthy individuals but can cause maternalfetal transmission in women who acquire primary Toxoplasma infection during pregnancy $(6,7)$. The risk of vertical transmission and associated problems are determined by the gestational age at which the primary infection is acquired. Transmission to the fetus increases from the first trimester (10 to $24 \%$ ) to the third trimester (60 to $90 \%$ ), but the potential of congenital defect is more severe with earlier infections $(8,9)$. Most pregnant women with acute acquired infection do not experience obvious symptoms or signs. A minority may experience malaise, low-grade fever, and lymphadenopathy (10). Severe clinical signs in the infected infant commonly observed in offspring of women whose infection was acquired early in gestation $(6,11)$. A minority may experience malaise, low-grade fever, and lymphadenopathy (5). In the immunocompetent subjects, Toxoplasma infection is often asymptomatic, and frequently results in the chronic persistence of cysts within host tissues, that probably lie dormant for life. In contrast, in immunocompromised subjects, it is always life threatening.

Diagnosis of toxoplasmosis in humans is performed using different techniques. Acute and latent $T$. gondii infections during pregnancy are mostly diagnosed by serological tests including detection of anti- $T$. gondii specific IgM and IgG antibodies (12). Latex agglutination (LA) testing, enzyme-linked immunosorbent assay (ELISA), and/or indirect fluorescent antibody testing (IFAT) are some of the tests that used to detect the antibodies (13). In our context, most studies on prevalence of $T$. gondii infections have relied on antibody detection, although this is associated with false positives. A more reliable way of 
diagnosing active infection is the use of molecular techniques such as PCR using blood, brain biopsy, and liver biopsy materials (14). However, this is very expensive and not easily available in most developing countries making its use in routine diagnosis not feasible. It is for this reason that diagnosis of toxoplasmosis in most health facilities in these countries still largely rely on serology, hence the use of this method in the current study

There is uneven distribution of $T$. gondii prevalence among pregnancy and childbearing age from different parts of the world. In Europe, the prevalence of Toxoplasmosis varies between $20-50 \%$ in the South and between $50-70 \%$ in the West (15). Seroprevalence of $10.3 \%$ and $69 \%$ have been reported from Japan (16) and Northeastern Brazil (17). In Africa, data on $T$. gondii infection during pregnancy is scanty and its burden in pregnant women is an under-estimated public health concern. In these countries, higher (up to $92.5 \%$ ) seroprevalence has been reported. However, the prevalence of infection varies widely between countries (from 10 to $80 \%$ ) and often within a given country or between different communities in the same region (14). Pregnant women are not routinely investigated for $T$. gondii during pregnancy, and follow-up hardly exists $(18,19)$. In Cameroon, Mbouo-Bandjoun in particular, the seroprevalence of $T$. gondii infection is $45.5 \%$ (20) which represents a real public health problem as there are limited researches that have been conducted about risk factors associated with such high rate.

At the Bamenda Regional Hospital (BRH) measurement of $T$. gondii immunoglobulins is part of the routine tests prescribed by consulting gynaecologists, however due to ignorance of the importance of this test and sometimes financial constraints, pregnant women often fail to have this test performed during the entire period of their pregnancies. Also, the diagnosis of $T$. gondii infection is solely based on a qualitative test, and only women with positive IgM are treated while those with positive are usually not tested further to confirm their diagnosis, and are therefore not treated. In addition, information is scarce on the seroprevalence of $T$. gondii infection in pregnant women particularly in the study area. It is for these reasons that the present study was undertaken, with the aim of determining the seroprevalence of $T$. gondii infection, and identifying associated risk factors among pregnant women attending the antenatal clinic (ANC) of the BRH, Cameroon.

\section{Materials and method:}

\section{Study design and setting}

This was a descriptive cross-sectional study involving pregnant women attending the antenatal clinic (ANC) at the Bamenda Regional Hospital (BRH) located in the capital city of North West Region of Cameroon. The ANC unit is part of the Obstetric and Gynaecologic department, one of the 21 departments that make up the second degree referral hospital. Its services include: reception/registration room, laboratory, two examination rooms and general conference hall where antenatal consultation and education of pregnant women take place. ANCs take place from Monday to Friday every week. This study was carried out for a period of four months ( $1^{\text {st }}$ January to $31^{\text {st }}$ April 2018).

\section{Sample size and sampling technique}

All participants, attendees of the ANC service, who met the inclusion criteria, were recruited over the study period, using a systematic random sampling method. After identification, the potential study participants were taken through the informed consent process whereby the study objectives, risks, benefits and study procedures were explained. A total of 127 pregnant women were enrolled among 243 who attended the ANC clinic during the study period.

\section{Data collection}

A pre-tested questionnaire was used to collect information by face-to-face interview on socio-demographic and economic status as well as epidemiological risk factors of $T$. gondii infection. Data was collected on the following variables: age, ethnic group, marital status, level of education, occupational status, age of pregnancy, area of residence, history of miscarriage and still births, owning of pets or domestic animals, types of pets, handling of pets litter, farm or gardening work, history of children with eye or head malformations, habit of consumption of undercooked meat, raw dried meat commonly known as 'Kilichi', raw vegetables, drinking water sources, and history of recent blood transfusion. The level of knowledge regarding toxoplasmosis and sources of information on $T$. gondii infection were also evaluated.

\section{Sample collection and processing}

Approximately $5 \mathrm{ml}$ of venous blood was collected aseptically from each participant into a plain dry. The blood sample was allowed to clot and centrifuged at 3,000 rpm for 5 minutes, and the serum was separated into another plain dry. The sera were tested for anti-T. gondii IgM and IgG antibody using the cassette and buffer technique (an immunochromatographic test also named Rapid Diagnostic Test (RDT)). For the samples with a positive IgG but negative IgM, the quantitative testing was then done using 
Enzyme Linked Immuno-Sorbant Assay (ELISA) test kit at the biochemistry lab, strictly following the manufacturer's instruction.

\section{Rapid immunochromatographic test for toxoplasmosis}

The sera were tested by the rapid ICT (cassette and buffer) test. During the period of collection, the test components were allowed to get to room temperature every morning. When the sera were ready to test, a test cassette was removed from the pouch, placed on a clean surface and labeled with the corresponding patient's code. One drop (about $30-45 \mu \mathrm{L}$ ) of the specimen was placed in the sample well using a plastic dropper. One drop of specimen diluent was then added to the specimen and the timer was set. After $15 \mathrm{mins}$ the cassette was examined for result. The cassette and buffer ICT test contains a build in control (C) line which develops after adding the specimen and sample diluent. If the ' $C$ ' line does not develop, the whole procedure is reviewed and the test repeated with a new cassette. The result was negative or nonreactive if only the ' $C$ ' line was present with the absence of any burgundy line in both the test lines ( $M$ and $G$ ) indicating that no anti-T. gondii Ig was detected in the specimen. The result was considered positive or reactive for; (i) anti-T. gondii IgM if only the $M$ line develops in addition to the 'C' line; (ii) anti-T. gondii IgG if only the ' $G$ ' line develops in addition to the ' $C$ ' line; and (iii) anti-T. gondii IgG and IgM if both the $G$ and $M$ lines develop, in addition to the ' $C$ ' line.

\section{ELISA test for toxoplasmosis}

Serum samples positive for IgG but negative for IgM in the rapid ICT were further tested using the ELISA Toxo (DRG kit, Germany) test. For this second testing, all specimens were refrigerated at $-10^{\circ} \mathrm{C}$. On test days, both the specimens and test components were allowed to thaw to room temperature. The different steps of the ELISA technique were then performed. Each patient specimen was diluted with the sample diluents (1 in 100) into new tubes and allowed to stand for 15 mins before the start of the assay. The required number of microliter strips or wells were labeled and inserted into the holder, with the first six corresponding to the blank, negative control, standards 1-3, and the positive control.

Briefly, $100 \mu \mathrm{L}$ each of the negative control, standards and positive control was dispensed in the corresponding well, while making sure the blank is always empty and dry. $100 \mu \mathrm{L}$ of each specimen was then dispensed into the corresponding wells as labeled, making sure to use each disposable tip only once. The wells were covered with the foil paper provided in the kit and allowed to incubate for 1 hour at $37^{\circ} \mathrm{C}$.
The content of the wells was then briskly shaken out and rinsed 5 times with the diluted wash solution $(300 \mu \mathrm{L}$ per well). The wells were stroked against an absorbent paper to make sure all the residual droplets and air bubbles were removed, as the precision of the result is directly affected by the quality of the washing. $100 \mu \mathrm{L}$ of the enzyme conjugate was then dispensed into each well except the blank and incubated at room temperature, making sure not to expose to direct sunlight. The content of the wells was briskly shaken out, the washing repeated as above, and the wells stroked against an absorbent paper. $100 \mu \mathrm{L}$ of substrate solution was then added to all the wells and incubated for $15 \mathrm{mins}$ at room temperature in the dark. $100 \mu \mathrm{L}$ of the stop solution was then added to each well and any blue color that developed during the incubation turned yellow and highly positive samples at times got dark precipitates. The wells were then inserted into the ELISA reader which has been pre-programmed and a graph of absorbance value (mean) of the negative control, standards and their respective concentrations. This was then used to calibrate the absorbance of each of the test specimens and gave corresponding values.

The normal value range for ELISA was established by the BRH laboratory, based on its patient's population in the geographical area; negative when $<45 \mathrm{IU} / \mathrm{mL}$, cut-off value at 50 $\mathrm{IU} / \mathrm{mL}$, grey zone (equivocal) between 45-55 $\mathrm{IU} / \mathrm{mL}$ and positive when $>55 \mathrm{IU} / \mathrm{mL}$. Patients with equivocal results were called 2 weeks later (according to diagnostic principles of $T$. gondii) and blood samples were recollected for confirmation of test results, either the negative (memory immunity) or positive serology (active infection).

\section{Data management and analysis}

All data from the questionnaire and laboratory record were analyzed using SPSS version 20.0 software package. Descriptive statistic was performed to describe demographic profile of the study participants. The univariate analysis involved frequency distributions for categorical variables, and descriptive statistics for continuous and discrete variables was done to give an understanding of the characteristics of the sample, as well as description of the response variables ( $T$. gondii infection). Bivariate analysis was used to investigate association between the response variable ( $T$. gondii infection) and sociodemographic and other variables of interest (risk factors). The $x^{2}$ test was used to test association between 2 categorical variables and $p$ value $<0.05$ was considered as statistically significant. 


\section{Ethical considerations}

Ethical clearance $\left(\mathrm{N}^{\circ} 2017 / 0051 \mathrm{H} / \mathrm{UBa} /\right.$

IRB) was obtained from the Institutional Review Board at the Faculty of Health Science of the University of Bamenda. The administrative authorizations were obtained from the Delegation of Public Health of the North West Region and the General Supervisor of the Bamenda Regional Hospital. Moreover, written informed consent was obtained from all study participants prior to interview and blood collection. Confidentiality of the collected information and laboratory test results was maintained, and used solely for research purposes and neither for stigmatization nor to generate profit. The results of the study were made available for all participants as they desire with the attending physician for further management of the cases.

\section{Results:}

A total of 127 pregnant women age 14 to 50 years (27.4 \pm 6.21 years) out of 243 who attended $\mathrm{BRH}$ ANC clinic were included and tested for anti-T. gondii IgG and IgM antibody. Of this, $43(33.9 \%)$ were IgG seropositive and 1 $(0.8 \%)$ was positive for both IgG and IgM. Table 1 shows the socio-demographic characteristics and obstetric history of the study participants with regard to seroprevalence of $T$. gondii infection. The age group 24 to 34 years had the highest seroprevalence $(48.0 \%)$. Majority of the participants $(91.3 \%)$ were Grassfield ethnic group and the least represented ethnic groups were the Beti and others (such as Sawa and Bakossi) with $1.6 \%$ each. No statistically significant association between $T$. gondii infection and the various ethnic groups was observed. Among the 127 women who took part in this study, the grassfield was the ethnic group more represented and more infected with $90.9 \%$ of positive cases (40/44). The majority (59.0\%) were married and represented $61 \%$ (27/44) of positive cases. There was no significant association between $T$. gondii infection and marital status of the participants. There was also no significant association between age of pregnancy, area of residence, history of miscarriage and stillbirth and $T$. gondii infection $(p>0.05)$. With respect to gestational age, most of the participants were in their first trimester (50.4\%) among which 54.5\% (24/44) were positive for $T$. gondii infection. Regarding the area of residence, $79.5 \%$ were living in urban areas among which $75 \%(33 / 44)$ were positive to T. gondii infection. Women with history of miscarriage represented $38.6 \%$ and $40.9 \%$ of positive cases, while those with a history of still birth $(11.8 \%)$ represented $11.4 \%$ of positive cases.

Table 2 depicts the seroprevalence of study participants and factors associated with $T$. gondii infection. Among the total respondents, 32 (37.0\%) own a pet and $21(16.5 \%)$ handled pet litters. There was a significant association between $T$. gondii infection and owing a pet $(p=0.013)$, and handling pet litters $(p=0.006)$. There was no significant association between $T$. gondii infection and farming or gardening, and source of drinking water $(p>0.05)$. However, among the 127 participants who practiced farming or gardening, $64(61.36 \%)$ were positive for $T$. gondii infection. With respect to sources of drinking water, 96/127 had tap water, and among these, 68.2\% were positive (30/44) for $T$. gondii infection. Ninety nine of 127 pregnant women responded that they consume raw fruits/vegetables, of which $81.8 \%$ were positive for T. gondii infection; 9 of 127 responded that they consume undercooked meat, of which $11.4 \%$ were positive to $T$. gondii infection; while $52.3 \%$ of those who consume raw dried meat were postive for $T$. gondii infection. There was no significant association between $T$. gondii infection and habit of consuming raw fruits/vegetables, undercooked meat, and raw dried meat. The pregnant women who had had blood transfusion in the year before their pregnancy represented $81.8 \%$ of positive cases but there was no significant association between $T$. gondii infection and history of blood transfusion. 
Table 1: Socio-demographic and obstetric characteristics of study participants in relation to seroprevalence of Toxoplasma gondii infection

\begin{tabular}{|c|c|c|c|c|c|}
\hline \multirow[t]{2}{*}{ Variables } & \multicolumn{2}{|c|}{ Seroprevalence } & \multirow{2}{*}{$\begin{array}{c}\text { Total }(\%) \\
n=127\end{array}$} & \multirow[t]{2}{*}{ OR $(95 \% \mathrm{CI})$} & \multirow[t]{2}{*}{ p value } \\
\hline & $\begin{array}{c}\text { Positive (\%) } \\
n=44\end{array}$ & $\begin{array}{c}\text { Negative (\%) } \\
n=83\end{array}$ & & & \\
\hline \multicolumn{6}{|c|}{ Age groups (years) } \\
\hline $14-24$ & $14(11,0)$ & $30(23,6)$ & $44(34.6)$ & $0.766(0.347-1.687)$ & 0.507 \\
\hline $24-34$ & $21(16.5)$ & $40(31.5)$ & $61(48.3)$ & $1.026(0.491-2.144)$ & 0.945 \\
\hline $34-44$ & $6(4.7)$ & $11(8.7)$ & $17(2.4)$ & $0.890(0.304-2.604)$ & 0.831 \\
\hline $44-50$ & $3(2.4)$ & $2(2.4)$ & $5(3,9)$ & $2.963(0.476-18.441)$ & 0.244 \\
\hline \multicolumn{6}{|l|}{ Ethnic group } \\
\hline Mbororo & $1(0.8)$ & $3(2.4)$ & $4(3.1)$ & $0.020(0.063-6.145)$ & 0.683 \\
\hline Grassfield & $40(31.5)$ & $76(59.8)$ & $116(91.3)$ & $0.921(0.254-3.335)$ & 0.900 \\
\hline Beti & $1(0.8)$ & $1(0.8)$ & $2(1.6)$ & $1.907(0.116-31.244)$ & 0.651 \\
\hline Bayangi & $1(0.8)$ & $2(1.6)$ & $3(2.4)$ & $0.942(0.083-10.686)$ & 0.961 \\
\hline Others & $1(0.8)$ & $1(0.8)$ & $2(1.6)$ & $1.907(0.116-31.244)$ & 0.651 \\
\hline \multicolumn{6}{|l|}{ Marital status } \\
\hline Single & $13(10.2)$ & 25 (19.7) & $38(29.9)$ & $0.973(0.437-2.164)$ & 0.946 \\
\hline Married & $27(21.2)$ & $48(37.8)$ & $75(59.0)$ & $1.158(0.549-2.44)$ & 0.700 \\
\hline Divorced & $1(0.8)$ & 0 & $1(0.8)$ & $5.894(0.235-147.799$ & 0.280 \\
\hline Cohabiting & $3(2.4)$ & $10(7.9)$ & $13(10.2)$ & $0.562(0.146-2.161)$ & 0.401 \\
\hline \multicolumn{6}{|c|}{ Level of education } \\
\hline FSLC & $12(9.4)$ & $18(14.2)$ & $30(23.6)$ & $1.354(0.582-3.150)$ & 0.481 \\
\hline Ordinary & $11(8.7)$ & $17(13.4)$ & $28(22.0)$ & $1.294(0.544-3.076)$ & 0.556 \\
\hline Advance & $9(7.1)$ & $19(15.0)$ & $28(22.0)$ & $1.031(0.423-2.513)$ & 0.946 \\
\hline Tertiary & $12(9.4)$ & $29(22.8)$ & $41(32.3)$ & $0.721(0.32-1.612)$ & 0.425 \\
\hline \multicolumn{6}{|c|}{ Employment status } \\
\hline Unemployed & $11(8.6)$ & $17(13.4)$ & $28(22.0)$ & $1.294(0.544-3.076)$ & 0.559 \\
\hline Public sector & $6(4.7)$ & $16(12.6)$ & $22(17.3)$ & $0.671(0.242-1.859)$ & 0.443 \\
\hline Private sector & $9(7.1)$ & $15(11.8)$ & $24(18.9)$ & $1.166(0.464-2.929)$ & 0.744 \\
\hline Self employed & $11(8.7)$ & $23(18.1)$ & $34(26.8)$ & $0.869(0.377-2.004)$ & 0.743 \\
\hline Student & $7(5.5)$ & $12(8.8)$ & $29(14.3)$ & $1.119(0.406-3.0827)$ & 0.827 \\
\hline \multicolumn{6}{|c|}{ Trimester of pregnancy } \\
\hline $1^{\text {st }}$ trimester & $24(18.9)$ & $40(31.5)$ & $64(50.39)$ & $1.290(0.619-2.685)$ & 0.496 \\
\hline $2^{\text {nd }}$ trimester & $18(14.2)$ & $38(29.9)$ & $56(44.1)$ & $0.819(0.391-1.718)$ & 0.599 \\
\hline $3^{\text {rd }}$ trimester & $2(1.6)$ & $5(3.9)$ & $7(5.5)$ & $0.761(0.141-4.095)$ & 0.750 \\
\hline \multicolumn{6}{|l|}{ Residence } \\
\hline Urban & $33(26.0)$ & $68(53.5)$ & $101(79.5)$ & $0.662(0.274-1.599)$ & 0.359 \\
\hline Rural & $10(7.9)$ & $15(11.8)$ & $25(19.7)$ & $1.333(0.542-3.279)$ & 0.531 \\
\hline Unknown & $1(0.8)$ & 0 & $1(0.8)$ & $0.215(0.026-1.749)$ & 0.150 \\
\hline \multicolumn{6}{|c|}{ History of miscarriage } \\
\hline Yes & $18(14.2)$ & $31(24.4)$ & $49(38.6)$ & $1.161(0.549-2.452)$ & 0.695 \\
\hline No & $22(17.3)$ & $52(41.0)$ & $74(58.4)$ & & \\
\hline \multicolumn{6}{|c|}{ History of still birth } \\
\hline Yes & $5(3.9)$ & $10(7.9)$ & $15(11.8)$ & $0.936(0.299-2.931)$ & 0.909 \\
\hline No & $39(30.7)$ & $73(57.5)$ & $112(88.2)$ & & \\
\hline
\end{tabular}

OR: Odd ratio, CI: Confidence interval, n: Frequency, \%: Percentages, FSLC: First School Living Certificate

Table 2: Seroprevalence rate and risk factors for Toxoplasma gondii infection among study participants

\begin{tabular}{|c|c|c|c|c|c|}
\hline \multirow[t]{2}{*}{ Variables } & \multicolumn{2}{|c|}{ Seroprevalence } & \multirow{2}{*}{$\begin{array}{l}\text { Total }(\%) \\
(n=127)\end{array}$} & \multirow[t]{2}{*}{ OR $(95 \% \mathrm{CI})$} & \multirow[t]{2}{*}{$p$ value } \\
\hline & $\begin{array}{c}\text { Positive (\%) } \\
(n=44)\end{array}$ & $\begin{array}{c}\text { Negative (\%) } \\
(n=83)\end{array}$ & & & \\
\hline \multicolumn{6}{|l|}{ Owning pet } \\
\hline Yes & $17(13.4)$ & $15(11.8)$ & $32(37.0)$ & $2.854(1.25-6.51)$ & 0.013 \\
\hline No & $27(21.3)$ & $68(53.5)$ & $85(74.8)$ & & \\
\hline \multicolumn{6}{|c|}{ Contact with cat } \\
\hline Yes & $8(6.3)$ & $6(4.4)$ & $14(10.7)$ & $2.851(0.921-8.829)$ & 0.069 \\
\hline No & $36(28.1)$ & $77(60.6)$ & $113(88.8)$ & & \\
\hline \multicolumn{6}{|c|}{ Handling pet litter } \\
\hline Yes & $13(10.2)$ & $8(6.3)$ & $21(16.5)$ & $3.931(1.48-10.42)$ & 0.006 \\
\hline No & $31(24.4)$ & $75(59.1)$ & $106(83.5)$ & & \\
\hline \multicolumn{6}{|c|}{ Farming/gardening } \\
\hline Yes & $27(21.3)$ & $37(29.1)$ & $64(50.4)$ & $1.975(0.937-4.161)$ & 0.075 \\
\hline No & $17(12.4)$ & $46(36.2)$ & $63(48.6)$ & & \\
\hline \multicolumn{6}{|c|}{ Source of drinking water } \\
\hline Tap & $30(21.9)$ & $66(52.0)$ & 96 (73.9) & $0.552(0.241-1.264)$ & 0.159 \\
\hline Spring & $7(5.5)$ & $7(5.5)$ & $14(11.0)$ & $2.054(0.671-6.289)$ & 0.207 \\
\hline Well & $5(3.9)$ & $6(4.7)$ & $11(8.7)$ & $1.645(0.472-5.730)$ & 0.434 \\
\hline Bottle & $2(1.6)$ & $3(2.4)$ & $5(3.9)$ & $1.413(0.227-8.776)$ & 0.712 \\
\hline Tap and stream & 0 & $1(0.79)$ & $1(0.79)$ & $0.618(0.025-15.488)$ & 0.769 \\
\hline \multicolumn{6}{|c|}{ Habit of eating raw fruits/vegetables } \\
\hline Yes & $36(28.8)$ & $63(49.6)$ & $119(78.0)$ & $1.429(0.571-3.572)$ & 0.446 \\
\hline & $8(5.9)$ & $20(15.7)$ & $28(21.9)$ & & \\
\hline \multicolumn{6}{|c|}{ Habit of eating undercooked meat } \\
\hline Yes & $5(3.94)$ & $4(3.15)$ & $9(7.09)$ & $2.532(0.644-9.961)$ & 0.184 \\
\hline No & $39(30.7)$ & $79(62.2)$ & $118(90.7)$ & & \\
\hline \multicolumn{6}{|c|}{ Habit of eating raw dried meat } \\
\hline Yes & $23(18.1)$ & $30(23.6)$ & $53(41.7)$ & $1.935(0.921-4.063)$ & 0.081 \\
\hline & $21(16.5)$ & $53(41.7)$ & $74(58.3)$ & & \\
\hline \multicolumn{6}{|c|}{ History of blood transfusion } \\
\hline Yes & $6(4.7)$ & $8(6.3)$ & $14(11.1)$ & $1.480(0.479-4.574$ & 0.495 \\
\hline No & $38(29.9)$ & $75(59.1)$ & $113(89.0)$ & & \\
\hline
\end{tabular}




\section{Discussion:}

The present study reports the seroprevalence of $T$. gondii infection among pregnant women in the BRH to be $35.4 \%$ (34.6\% for IgG and $0.8 \%$ for both IgG and IgM. This rate is similar to the those reported in Nigeria by Umar et al., (21) and Bello et al., (2), but lower than rates previously reported by Guemgne et al., (20), Nguefack et al., (21) and Njunda et al., (22) in Cameroon and Yohanes et al., (23) in Ethiopia. In the study by Njunda et al., (22), the rate was $70 \%$ in pregnant women, however, the study looked at a metropolitan population in a third degree referral health facility (Douala General Hospital) whereas in the present study, it was conducted in a second degree referral unit $(\mathrm{BRH})$. Also Douala is a town with a more precarious living condition which could also explain the higher prevalence reported in that study. In the study by Yohanes et al., (23) on 232 pregnant women, the overall seroprevalence of $T$. gondii infection was $79.3 \%$ with 175 (75.43\%) positive for IgG, 9 (3.9\%) for IgM, 2 of which were positive for both IgG and IgM. Another study carried out by Wams et al., (24) in Njinikom-Cameroun reported a prevalence of $54.5 \%$, which is also higher than the rate in our study.

The observed differences in the seroprevalence rate of anti- $T$. gondii infection may be due to differences in the two study populations and the sample size. In fact, the present study was confined to an urban population in Bamenda, as opposed to the rural population in the study by Wams et al., (24). As such there is perceived higher level of awareness, and preventive measures about $T$. gondii in our study population. The variation in seroprevalence of $T$. gondii infection may be due to differences in geographical distribution of the parasite, socioeconomic, personal hygienic practices, and feeding habit of the study participants. In addition, differences in test methods may also account for the variation.

The presence of IgM antibodies during pregnancy indicates acute $T$. gondii infection with high risk of maternal-fetal transmission (25). A previous study has estimated that in the absence of treatment, the risk of congenital infection from acute $T$. gondii infection during pregnancy is about $50 \%$ (26). Early diagnosis of infections in pregnant mothers is of great importance so that measures that can reduce the risk of transmission and possible sequelae in the newborn are promptly initiated. Therefore, screening of pregnant women for Toxoplasma infection should be considered as a part of the routine investtigation during ANC follow up.

Our study did not show any statistically significant association between the trimester of pregnancy and Toxoplasma gondii infection, which agrees with studies from Egypt by Mandour et al., (27) in 2017 and Yemen by Saif et al., (28) in 2014 but disagrees with those of Khan et al., (29), Alanyande et al., (30) and Bello et al., (2) who reported significant association. A significant association between pet ownership and $T$. gondii infection was found. Similarly, Khan et al., (29) in 2011 and Yohanes et al., (23) in 2017 showed coherent associations. Contrarily, studies by Pal et al., (31) and Saif et al., (28) showed different results. There was no significant association between cat ownership and $T$. gondii infection, similar to what has been reported by Ebrahimzadeh et al., (32), Shao et al., (15), Murebwayire et al., (14), Jumaian (33), Mandour et al., (18), Makiani et al., (34), Njunda et al., (22), Wam et al., (24)] and Saif et al., (28). However, many studies among which Moura et al., (1), Dwinata et al., (3), Umar et al., (25), Yohanes et al., (23), Agmas et al., (36), Nissapatorn et al., (37), Duan et al., (38) and Nguefack et al., (21) demonstrated the contrary. This may be explained by the fact that the presence of cat in the house is not enough to cause zoonosis but rather handling of cats' litter is of more importance. Our study demonstrated a significant association between handling of pets' litter and $T$. gondii infection, a finding that agrees with that of Dwinata et al., (3) in 2016.

There was no significant association between farming or gardening and $T$. gondii infection, which is similar to studies by Moura et al., (1), Agmas et al., (36), Makiani et al., (34), Nissapatorn et al., (37), and Yohanes et al., (23) but contradicts the studies by Jumaian et al., (33) in 2005 and Mandour et al., (18) in 2017. The findings of these studies appeared different because contamination of soil occurs principally after defecation of cats, and contamination rate largely depend on cat density, with urban areas where cat density is low tending to have low soil contamination rate, and therefore low prevalence of $T$. gondii infection.

\section{Conclusion:}

This study reports seroprevalence of $T$. gondii infection in pregnancy to be $34.6 \%$. The risk factors associated with $T$. gondii infection include pets' ownership and handling of their litters. There is need for routine screening of pregnant women for $T$. gondii infection during ANC and treatment of cases. Education on hygiene and awareness of risk exposures regarding $T$. gondii infection to minimize its effects among pregnant women and the general population are imperative.

\section{Funding:}

The authors received no funding for the study 


\section{Acknowledgments:}

The authors are grateful to staff members of Bamenda Regional Hospital ANC clinic and Biochemistry laboratory for their cooperation during data collection and laboratory work respectively, as well as to the study participants.

\section{Authors' contributions:}

NNF and FP were involved in the design of the study, drafted the protocol with input from other authors. NNF, DWP and KFHL monitored laboratory work and analyzed the data. GBM performed the laboratory analysis and collected the results. NNF and KFHL drafted and finalized the manuscript for publication. DWP and TWA edited the manuscript. All authors contributed to the writing of the paper and approved the final version.

\section{Conflict of interest:}

\section{Authors declared no conflict of interest}

\section{References:}

1. De Moura, F. L., Regina, M., Amendoeira, R., et al. Prevalence and risk factors for Toxoplasma gondii infection among pregnant and postpartum women attended at public healthcare facilities in the City of Niterói, State of Rio de Janeiro, Brazil. J Braz Soc Trop Med. 2013; 46 (2): 200-207.

2. Bello, H. S., Umar, Y. A., Abdulsalami, M. S., et al. Seroprevalence and Risk Factors of Toxoplasmosis among Pregnant Women Attending Antenatal Clinic in Kaduna Metropolis and Environs. Int J Trop Dis HIth. 2017; 23 (3): 1-11.

3. Dwinata, I. M., Sutarga, I. M., and Damriyasa, I. M. The potential risk factors for toxoplasmosis in balinese pregnant women-indonesian. Bali Medical Journal 2016 ; 5 (1): 116-118.

4. Jones, J. L., Lopez, A., Wilson, M., et al. Congenital Toxoplasmosis: A Review Obstetr Gynecol Surv. 2001; 56 (5): 296-305.

5. Tenter, A. M., Heckeroth, A. R., and Weiss, L. M. Toxoplasma gondii from animals to humans, Int J Parasitol. 2000; 30 (12-13): 1217-1258.

6. Montoya, J. G., and Liesenfeld, O. Toxoplasmosis. Lancet. 2004; 363 (9425): 1965-1976.

7. Kieffer, F., and Wallon, M. Congenital toxoplasmosis, Handbook of Clinical Neurology. 2013; 112 : 10991101.

8. Chaudhry, S. A., Gad, N., and Koren, G. Toxoplasm osis and pregnancy. Can Fam Physician. 2014; 60: 334-336.

9. Uttah, E., Ogban, E., and Okonofua, C. Toxoplasmosis: A global infection, so widespread, so neglected. Int J Sci Res. 2013; 3 (6): 1-6.

10. Lin, Y. L., Liao, Y. S., Liao, L. R., et al. Seroprevalence and sources of Toxoplasma infection among indigenous and immigrant pregnant women in Taiwan. Parasitol Res. 2008; 103(1): 67-74.

11. Boyer, K. M., Holfels, E., Roizen, N., et al. Risk factors for Toxoplasma gondii infection in mothers of infants with congenital toxoplasmosis: Implications for prenatal management and screening. Am J Obstetr Gynaecol. 2005; 192 (2): 564-571.
12. Montoya, J. G. Laboratory diagnosis of Toxoplasma gondii infection and Toxoplasmosis. J Infect Dis. 2002, 185 (1): S73-82.

13. Montoya, J. G., and Remington, J. S. Management of Toxoplasma gondii infection during pregnancy. Clin Infect Dis. 2008; 47 (4): 554-566.

14. Murebwayire, E., Njanaake, K., Ngaboniziza, J. C. S., et al. Seroprevalence and risk factors of Toxoplasma gondii infection among pregnant women attending antenatal care in Kigali, Rwanda, Tanzania J HIth Res. 2017; 19 (1): 1-8.

15. Shao, E. R., Ndazana, S. G., Chacha, W., et al. Seroprevalence and factors associated with Toxoplasma gondii infection among pregnant women attending antenatal care in the referral hospital in Tanzania. Ann Clin Laboratory Res. 2015; 3 (2): 171-176.

16. Sakikawa, M., Noda, S., Hanaoka, M., et al. Antitoxoplasma antibody prevalence, primary infection rate, and risk factors in a study of Toxoplasmosis in 4,466 pregnant women in Japan. Clin Vaccine Immunol. 2012; 19 (3): 365-367.

17. Sroka, S., Bartelheimer, N., Winter, A., et al. Prevalence and risk factors of toxoplasmosis among pregnant women in Fortaleza, Northeastern Brazil. Am J Trop Med Hyg. 2010; 83 (3): 528-533.

18. Ayi, I., Edu, A. A. S., Apea-Kubi, K. A., et al. Seroepidemiology of toxoplasmosis amongst pregnant women in the greater Accra region of Ghana. Ghana Med J. 2009; 43 (3):107-114.

19. Alsammani, M. A. Sero-epidemiology and risk factors for Toxoplasma gondii among pregnant women in Arab and African countries. J Parasit Dis. 2016; 40 (3): 569-579.

20. Guemgne, T. F., Makou T. E., Gamago, G. A., et al. Seroprevalence of Toxoplasmosis and associated risk factors of Toxoplasma gondii infection in pregnant women at the Protestant hospital, Mbouo-Bandjoun, Cameroon. Afr J Clin Exper Microbiol. 2019; 20 (3): 221-230.

21. Nguefack, C.T., Meumeu, I.K., Ngaba, G.P., et al. Prevalence and factors associated with Toxoplasma gondii immunization among pregnant women in Douala, Cameroon. J Women Health. 2016; 5: 6.

22. Njunda, A. L., Assob, J. C. N., Nsagha, D. S., et al. Seroprevalence of Toxoplasma gondii infection among pregnant women in Cameroon. J Publ HIth Afr. 2011; 2 (2): e24.

23. Yohanes, T., Zerdo, Z., Chufamo, N., et al. Toxoplasma gondii Infection: Seroprevalence and associated factors among Pregnant Women Attending in Antenatal Clinic of Arba Minch Hospital, South Ethiopia: Cross Sectional Study. Translational Biomed J. $2017 ; 8$ (1): 105 (1-7).

24. Wam, E. C., Sama, L. F., Ali, I. M., et al. Seroprevalence of Toxoplasma gondii IgG and IgM antibodies and associated risk factors in women of child bearing age in Njinikom, NW Cameroon. BMC Research Notes. 2016; 9 (406): 1-8.

25. Tekkesin, N. Diagnosis of toxoplasmosis in pregnancy: A review. HOAJ Biology. 2012; 35 (1): 18.

26. Paquet, C., Yudin, M. H., Allen, V. M., et al. Toxoplasmosis in pregnancy: Prevention, screening, and treatment. J Obstetr Gynaecol Canada. 2013; 35 (1): 78-81.

27. Mandour, A. M., Mouhamad, M. M. E., Eldeek, H. M. E., et al. Prevalence of congenital Toxoplasmosis in Pregnant women with complicated pregnancy outcomes in Assiut Governorate, Egypt. J Adv Parasitol. 2017; 4 (1): 1-8.

28. Saif, N., Al Ameeri, G., Alhweesh, M., et al. Seroprevalence of Toxoplasmosis in Pregnant Women in Taiz-Yemen. Int J Curr Microbiol Appl Sci. 2014; 3 (7): 680-690.

29. Khan, S. N., Khan, S., Ayaz, S., et al. Seroprevalance and risk factors of toxoplasmosis among pregnant women in District Kohat, Khyber Pakhtunkhwa Pakistan. World Appl Sci J. 2011; 14 (7): 1032-1036. 
30. Alayande, M. O., Edungbola, L. D., Fabiyi, J. P., et al. Occurrence of antibody to Toxoplasma infection among pregnant women with obstetric histories and at different trimesters in Sokoto, Northwest Nigeria. Am J Res Comm 2013; 1 (9): 240-247.

31. Pal, S., Das, N., and, Pal, D. Seroprevalence and risk factors of Toxoplasma gondii in pregnant women in Kolkata, India. J Rec Adv Appl Sci. 2011; 26 (10): 2733.

32. Ebrahimzadeh, A., Mohammadi, S., Salimikhorashad, A., et al. Seroprevalence of Toxoplasmosis among Pregnant Women Referring to the Reference Laboratory of Zahedan, Iran. Zahedan Journal of Research in Medical Science. 2013; 15 (12): 32-35.

33. Jumaian, N. F. Seroprevalence and risk factors for Toxoplasma infection in pregnant women in Jordan. Eastern Mediterr HIth J. 2005; 11 (1-2) :45-51.

34. Makiani, M. J., Davoodian, P., Golsha, R., et al. Original Article Seroepidemiology and risk factors of Toxoplasmosis in the first trimester among pregnant women. International Electronic Journal of Medicine. 2012; 12 (2): 12-17.

35. Umar, H. A., Olonitola, O. S., Suleiman, A. B., et al. Seroprevalence and risk factors of Toxoplasma gondii infection among pregnant women attending antenatal care in Kano Metropolis, Nigeria. Nig J Sci Res. 2016; 15 (3).

36. Agmas, B., Tesfaye, R., and Koye, D. N. Seroprevalence of Toxoplasma gondii infection and associated risk factors among pregnant women in Debre Tabor, Northwest Ethiopia. BMC Research Notes. 2015; 8 (1): 107.

37. Nissapatorn, V., Suwanrath, C., Sawangjaroen, N., et al. Toxoplasmosis: serological evidence and associated risk factors among pregnant women in Southern Thailand. Am J Trop Med Hyg. 2011; 85 (2): 243-247.

38. Duan, C., Ning, Z., Hao, W., et al. Toxoplasma gondii infection among pregnant women in Guangdong. J Med Microbiol Diagn. 2012; 1 (3): 10-13. 